\title{
Museu Histórico Nacional
}

Angela Cardoso Guedes

Assessora de Comunicação do Museu Histórico Nacional. Jornalista, doutora em Ciência da Informação (UFRJ/IBICT).

E-mail: mhn02@visualnet.com.br

Resumo: Localizado no centro histórico do Rio de Janeiro, num dos mais significativos conjuntos arquitetônicos da cidade, o Museu Histórico Nacional é ligado ao Instituto Brasileiro de Museus e preserva o maior acervo sob a guarda do Ministério da Cultura. Reúne cerca de 277.490 itens, dentre os quais a maior coleção de numismática da América Latina, bem como carruagens históricas, porcelanas, indumentária civil e militar, armaria, esculturas, pinturas, obras raras e documentos manuscritos e iconográficos. Sede da primeira escola de museologia do país, hoje funcionando na UNIRIO, mantém intensa atividade de pesquisa e editoração, além de oferecer ao público exposições temporárias e de longa duração, cursos e seminários, visitas monitoradas às escolas, treinamento de professores e projetos que visam democratizar 0 acesso de todos os segmentos sociais ao Museu..

Palavras-chave: Museu Histórico Nacional, museu, cultura, arte, educação.
Abstract: Situated in the historical area of Rio de Janeiro, in one of the city's most important architectural complexes, the National Historical Museum, an integrant of the Brazilian Institute of Museums, is the guardian of the largest collection of cultural heritage of the Brazilian Ministry of Culture. With more than 277. 500 items, among which the largest numismatics' collection of Latin America, sculptures, iconographic and manuscripts documents, paintings, rare masterworks, civilian and military garments, gunnery, ancient historical vehicles, toys and other significant objects from native Brazilian and African cultures. Host to the first Museology school in Brazil - nowadays located at UNIRIO - the museum develops intense research and editorial activities, offers international seminars, courses, training programs for teachers and guided tours to the long duration and temporary exhibitions for elementary and second grade students. It also has special projects aiming to enhance the democratic access of all of the various strata of Brazilian society.

Keywords: National Historical Museum, museum, culture, art, education.

Numa ponta que avançava sobre o mar, posteriormente conhecida como Ponta do Calabouço, entre as praias de Piaçaba e Santa Luzia, no centro histórico do Rio de Janeiro, os portugueses construíram em 1603 a Fortaleza de Santiago, origem do conjunto arquitetônico que hoje abriga o Museu Histórico Nacional.

Ao longo dos séculos, outras edificações somaram-se à Fortaleza, como a Prisão do Calabouço (1693), destinada a escravos faltosos. Da fortaleza e da prisão restam, no entanto, apenas as fundações. Em 1762, foi construída a Casa do Trem para a guarda do trem de artilharia (armas e munições), e instalada meio século depois a Academia Militar, a primeira instituição brasileira de ensino superior e origem da primeira escola de engenharia do país. Em 1764, 
comunicação \& educação • Ano XV • número 3 • set/dez 2010

foi edificado o Arsenal de Guerra que, com a chegada da corte portuguesa, passou a ter uma organização semelhante à de Lisboa, sendo então denominado Arsenal Real do Exército e estando apto a produzir munição para as tropas reais. Posteriormente, em 1835, um quartel para abrigar as tropas militares veio somar-se ao Arsenal.

Por sua localização estratégica para a defesa da Baía da Guanabara e da própria cidade, a região foi uma área militar até 1908, quando o Arsenal de Guerra foi transferido para a Ponta do Caju e a região da Ponta do Calabouço entrou num período de decadência. No entanto, na década de 1920, a região foi aterrada, reurbanizada e dinamizada para acolher a Exposição Internacional comemorativa do Centenário da Independência do Brasil. As edificações do antigo Arsenal de Guerra foram ampliadas e embelezadas, com decoração característica da arquitetura neocolonial, e abertas ao público em 1922, abrigando o Palácio das Grandes Indústrias, um dos mais visitados pavilhões da Exposição do Centenário, e duas galerias do Museu Histórico Nacional, criado naquele mesmo ano pelo presidente Epitácio Pessoa, atendendo ao anseio de intelectuais da época, liderados por Gustavo Barroso, por dotar o Brasil de um museu dedicado à história nacional.

Ao longo do século XX, o Museu Histórico Nacional, ligado ao Instituto Brasileiro de Museus, foi ampliando o seu acervo e passando a ocupar todo o conjunto arquitetônico da Ponta do Calabouço. Hoje mantém sob a sua guarda o maior acervo do Ministério da Cultura, reunindo cerca de 277.490 itens - dentre

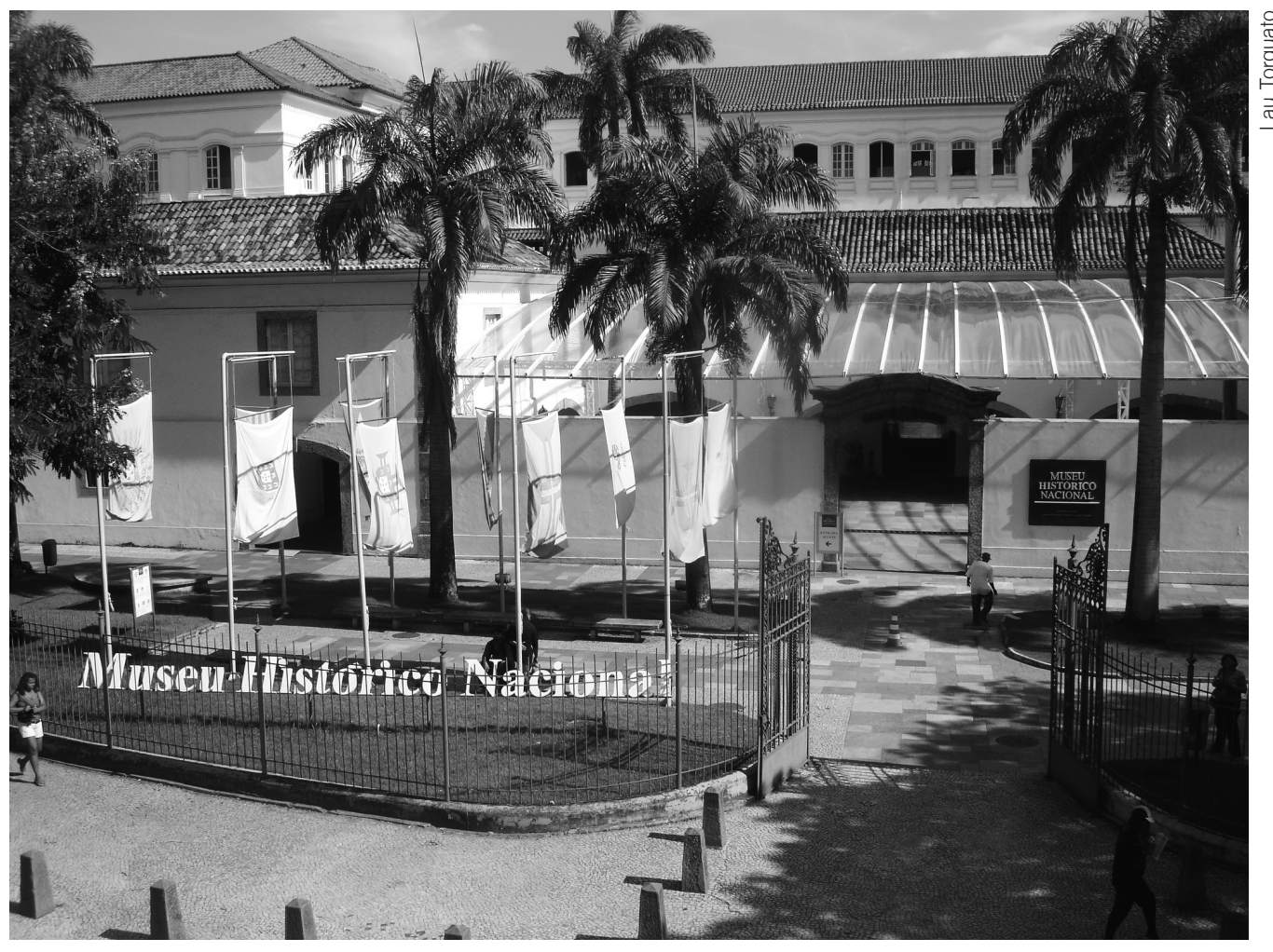

Fachada do Museu Histórico Nacional (antigo Arsenal de Guerra). 
os quais a mais significativa coleção de numismática da América Latina, bem como carruagens históricas, porcelanas, indumentária civil e militar, armaria, esculturas, pinturas, obras raras e documentos manuscritos e iconográficos, além de peças do cotidiano atual, tais como brinquedos, telefones celulares, cartões telefônicos etc.

Nos últimos anos, o Museu Histórico Nacional passou por um processo de restauração e modernização para recuperar a arquitetura original, integrar espaços e ampliar áreas abertas ao público, aprimorar os serviços oferecidos aos visitantes, democratizar o acesso dos mais diversos segmentos da sociedade e permitir uma circulação e um percurso adequados ao discurso museográfico.

Sede da primeira escola de museologia do país, hoje funcionando na UNIRIO, mantém intensa atividade de pesquisa e editoração, além de oferecer cursos e seminários, visitas monitoradas às escolas, treinamento de professores e projetos dedicados a menores carentes, portadores de deficiências e terceira idade.

\section{EXPOSIÇÕES DE LONGA DURAÇÃO}

O Museu Histórico Nacional oferece um circuito de exposições de longa duração, que está sendo revitalizado e concentrado no segundo pavimento do antigo Arsenal de Guerra e deverá estar totalmente concluído ainda em 2011. Peças contemporâneas e recursos multimídia são utilizados para auxiliar o visitante na compreensão de nossa história.

A única exposição de longa duração a permanecer no pavimento térreo é a referente aos meios de transporte, Do Móvel ao Automóvel - Transitando pela

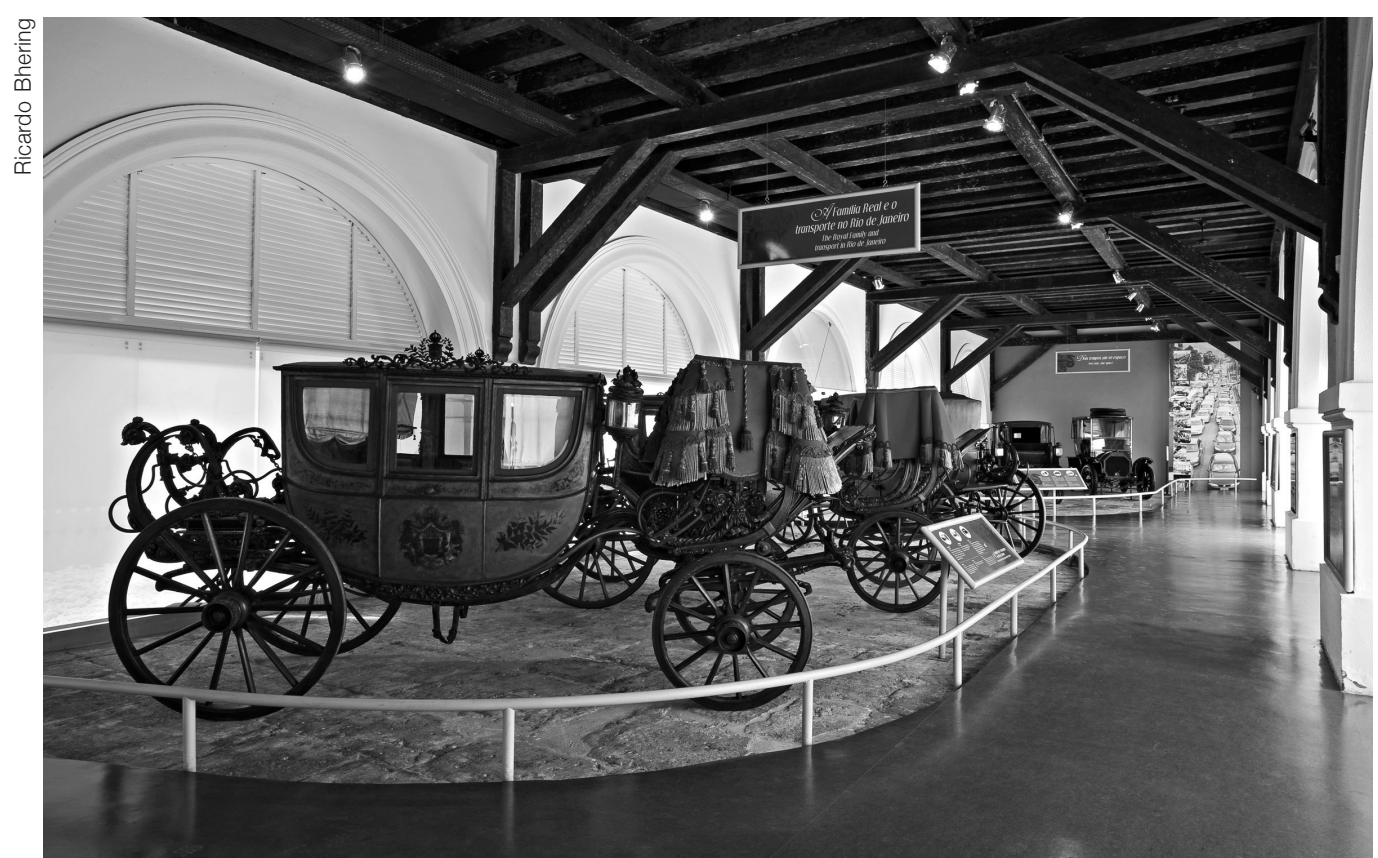

Exposição "Do Móvel ao Automóvel - Transitando pela História". 
comunicação \& educação • Ano XV • número 3 • set/dez 2010

História, devido às dimensões do acervo. A exposição reúne cadeirinhas de arruar, berlindas, traquitanas e até um automóvel do início do século XX, o Protos, que pertenceu ao Barão do Rio Branco. Veículos da Casa Real portuguesa e da família imperial brasileira também integram a exposição.

No pavimento térreo o visitante tem acesso, ainda, às galerias de exposições temporárias, ao auditório com capacidade de 200 lugares, onde são realizados seminários e concertos musicais, entre outras atividades, ao Café Histórico, à Loja do Museu e ao Hall dos Arcazes, decorado com onze pinturas cusquenhas dos séculos XVII, XVIII e XIX, que exemplificam a cultura peruana e a influência da colonização espanhola na América Latina.

A visita ao circuito de longa duração inicia-se com a apresentação de uma multivisão sobre a trajetória do Museu, localizado numa ampla galeria com teto decorado com magnífica pintura de Carlos Oswald. A seguir, o visitante é introduzido à pré-história brasileira e aos primeiros habitantes da terra - nossos índios -, na exposição Oreretama. Destaque para a ambientação de uma caverna pré-histórica da Serra da Capivara, com desenhos rupestres representando cenas da vida naquela época.

Já a exposição Portugueses no Mundo inicia-se com a exibição de um multimídia sobre a expansão portuguesa através das grandes navegações, com ênfase na colonização do Brasil. São abordados o período da União Ibérica, as presenças francesa e holandesa no Brasil dos séculos XVI e XVII, a expansão territorial da então colônia, a exploração do ouro e do diamante nas Minas Gerais e seu reflexo na estética do Barroco, com o aumento do número de igrejas, irmandades

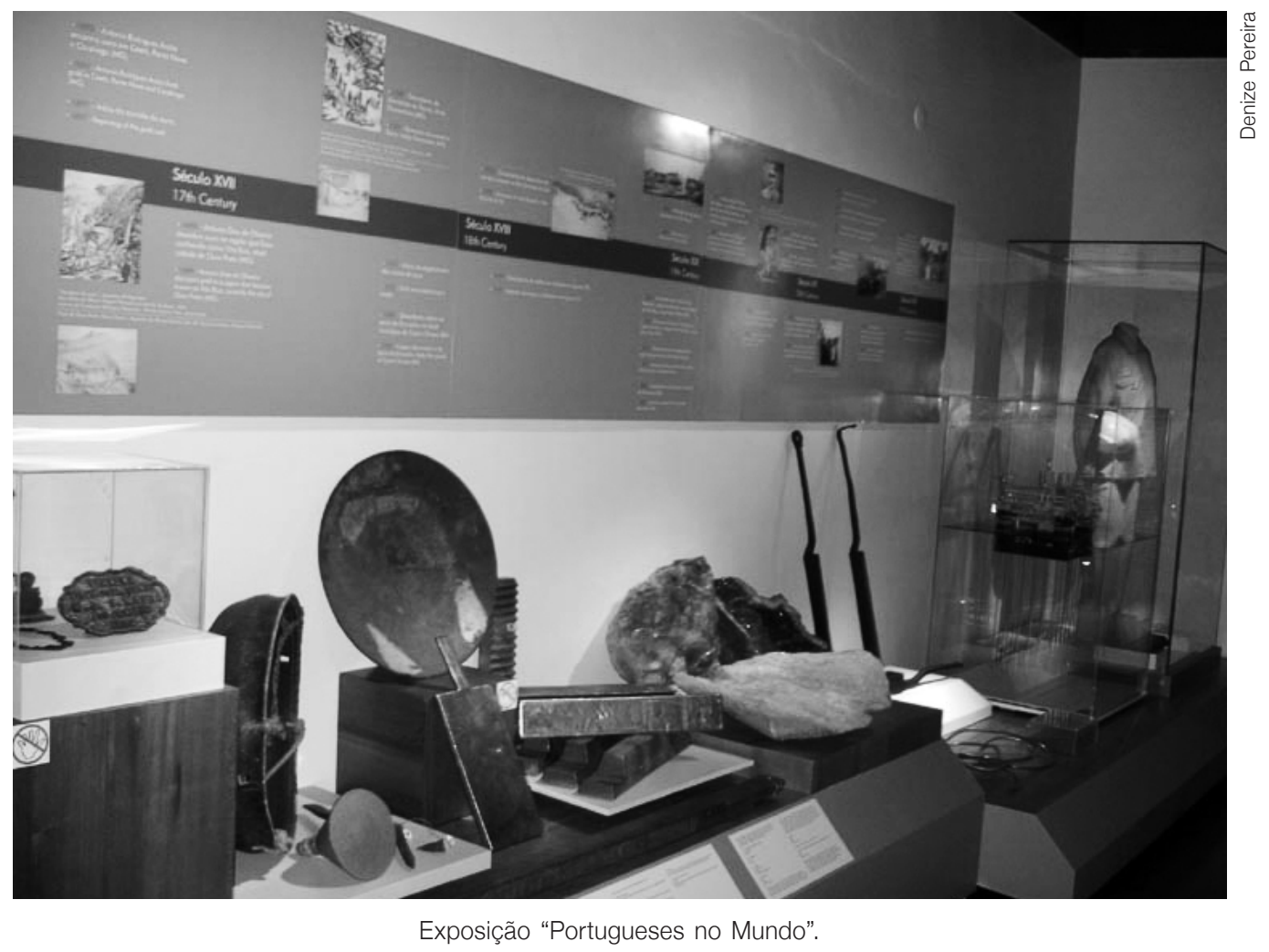


e produção de imaginária religiosa cristã. Complementando a exposição, uma linha do tempo representa as riquezas da terra, a exploração do ouro até o petróleo a ser extraído do pré-sal. Uma próxima galeria a ser aberta ainda em 2010 destacará a influência do negro na formação da identidade nacional e os reflexos da chegada da corte portuguesa em 1808 na história do Brasil.

As exposições A formação da nação, abrangendo o Brasil após a Independência de Portugal, e Cidadania em construção, referente ao país após a Proclamação da República, serão inauguradas até meados de 2011. Ainda no segundo pavimento, o visitante tem acesso à exposição Farmácia Homeopática Teixeira Novaes - uma reconstituição minuciosa da tradicional farmácia que funcionou de 1847 a 1983 na Rua Gonçalves Dias, no centro do Rio de Janeiro -, que exemplifica aspectos da saúde e do comércio no Brasil. Nas galerias da Casa do Trem, que abriga o acervo de numismática, o maior do gênero existente na América Latina, estão disponíveis outras duas exposições. As Moedas Contam a História engloba desde os primeiros sistemas de troca utilizados pela humanidade até a implantação da moeda unificada - o Euro -, para facilitar as transações comerciais entre os diversos países que integram a União Europeia no século XXI. Já a exposição Coleção de Moedas - Uma Outra História, recria um antigo Gabinete de Numismática, mostrando a formação da coleção de moedas e de outras peças numismáticas do Museu.

Além das exposições, o Museu dispõe de três agradáveis pátios internos: o Pátio da Minerva, entrada principal do Museu, Pátio Gustavo Barroso e Pátio dos Canhões, reunindo ali a importante coleção de canhões portugueses, ingleses, franceses e brasileiros.

\section{ARQUIVO HISTÓRICO}

Reúne 54.600 documentos manuscritos e iconográficos relacionados à História do Brasil, divididos em coleções que, entre outras, abrangem a família imperial brasileira, o compositor Carlos Gomes, a documentação pessoal do Ministro Miguel Calmon Du Pin e Almeida, aquarelas de indumentária civil e militar, fotos do Rio de Janeiro e da Revolta da Armada do espanhol Juan Gutierrez e caricaturas de RIAN.

Consulta mediante agendamento prévio através do telefone: (21) 2550-9268.

\section{BIBLIOTECA}

Reúne 56.510 publicações versando sobre História, História da Arte, Museologia, Heráldica, Numismática, Genealogia e Moda. Em 1999, com o apoio da empresa DocPro, foi lançado o CD-ROM Coletânea dos Anais do Museu Histórico Nacional - 1940 a 1998, vindo ao encontro de inúmeras solicitações por volumes já esgotados. A Biblioteca Virtual MHN/DocPro disponibiliza ao público a versão atualizada desse CD-ROM e possibilita a pesquisa on-line de parte do 
comunicação \& educação • Ano XV • número 3 • set/dez 2010

acervo do Museu. Consulte a Biblioteca Virtual em: <http://www.docpro.com. $\mathrm{br} / \mathrm{mhn} /$ bibliotecadigital.html $>$.

Consulta mediante agendamento prévio através do telefone: (21) 2550-9251 e também disponível em: <http://mhn.phlnet.com.br $>$.

\section{SETOR EDUCATIVO}

O setor oferece uma série de atividades diversas voltadas a alunos e professores, tais como Projeto Espaço Museu - Construção do Saber, visando preparar professores e guias de turismo que agendam visitas para grupos; Descobrindo o Museu, com visitas aos bastidores do Museu, cursos diversos para o público em geral e projetos dirigidos a instituições de ensino. Agendamento através dos telefones: (21) 2550-9260/2550-9261, ou do e-mail: mhnatividadeseducativas@ gmail.com.

\section{SETOR DE PROJETOS SOCIAIS}

Dedicado a democratizar o acesso dos segmentos sociais menos privilegiados ao Museu, o setor oferece atividades gratuitas a menores carentes, portadores de necessidades especiais e terceira idade.

Informações através do telefone: (21) 2550-9239, ou do e-mail projetossociaismhn@gmail.com.

\section{SERVIÇO}

\section{Museu Histórico Nacional}

Endereço: Praça Marechal Âncora - Próximo à Praça XV

CEP 20021-200 - Centro - Rio de Janeiro-RJ

Tel.: (21) 25509220/25509224

Horários de visitação: de terça a sexta-feira, das $10 \mathrm{~h}$ às $17 \mathrm{~h} 30$. Fechado às segundas-feiras (mesmo nos feriados). Sábados, domingos e feriados, das $14 \mathrm{~h}$ às $18 \mathrm{~h}$. Ingresso: $\mathbf{R} \$ 6,00$ (seis reais). Estão isentos de pagamento (mediante comprovação): crianças até 5 anos de idade; sócios do ICOM - International Council of Museum; funcionários do IPHAN e do IBRAM; alunos e professores das escolas públicas federais, estaduais e municipais; brasileiros maiores de 65 anos; guias de turismo e estudantes de Museologia. Alunos agendados da rede particular de ensino e brasileiros maiores de 60 anos e menores de 65 anos pagam a metade do valor. Aos domingos, a entrada é franca.

Site: <http://www.museuhistoriconacionalm.br>

E-mail: mhn02@visualnet.com.br 